JEL Classification: G21, G28, F36

Keywords: banking stability, interconnectedness, network analysis, banking crises

\title{
The Bright and the Dark Side of Cross-Border Banking Linkages*
}

\author{
Martin ČIHÁK_International Monetary Fund (mcihak@imf.org) and World Bank \\ (mcihak@worldbank.org),corresponding author \\ Sònia MUÑOZ_International Monetary Fund (smunoz@imf.org), corresponding author \\ Ryan SCUZZARELLA—International Monetary Fund (rscuzzarella@imf.org)
}

Abstract

When a country's banking system becomes more linked to the global banking network, does that system get more or less prone to a banking crisis? Using simulations and econometric estimates based on a world-wide dataset, we find an M-shaped relationship between the stability and the interconnectedness of a country's banking sector. For banking sectors that are not very connected to the global banking network, increases in interconnectedness are associated with a reduced probability of a banking crisis, but once the interconnectedness reaches a certain value, further increases in interconnectedness can increase the crisis probability. Interestingly, it matters whether the linkages are primarily in terms of the banks' assets or liabilities, with the relationship between interconnectedness and crisis probability being stronger for liabilities. Our findings suggest that it may be beneficial for policies to support greater interlinkages for less connected banking systems, but only up to a point.

\section{Introduction}

One of the hallmarks of financial globalization has been growth in crossborder linkages (exposures) among banks. On the positive side, these linkages have been associated with new funding and investment opportunities, contributing to rapid economic growth in many countries (especially in the early part of the 2000s). But the growing financial linkages also have a "dark side": ${ }^{1}$ the increased cross-border interconnectedness has made it easier for disruptions in one country ${ }^{2}$ to be transmitted to other countries and mutate into systemic problems with global implications.

The potential harmful consequences of cross-border interconnectedness for domestic banking sector stability have been illustrated rather dramatically during the recent global financial crisis, when shocks to one country's financial system were rapidly transmitted to many others. One of the upshots of the crisis is that considerable efforts have been devoted to better measuring the "systemic importance" of jurisdictions around the world. There is a growing consensus that interconnectedness, together with size, should be a key variable in assessing the systemic importance

\footnotetext{
* The views expressed in this article are those of the authors and do not necessarily represent those of the IMF or the World Bank. The article benefitted from comments by Dimitri Demekas, Eugenio Cerutti, Stijn Claessens, Camelia Minoiu, and two anonymous referees. We thank Zachary Neal and Goetz von Peter for sharing their codes and unpublished papers. Any remaining errors are ours.

${ }^{1}$ The literature suggests that various aspects of finance have both a "bright side" and a "dark side" (see, for example, the discussion of the "dark side" of bank wholesale funding in Huang and Ratnovski, 2010).

2 Throughout the article, the terms "country" and "jurisdiction" refer to a geographic entity for which banking and other statistics are reported separately.
} 
of a jurisdiction from the viewpoint of financial stability (IMF, BIS, and FSB, 2009; IMF, 2010).

This article aims to answer the following key question: when a country's banking system gets more linked to the global banking network, does it become more stable, or less stable? The answer to this question is obviously relevant for policymakers and regulators in individual countries. To the extent that interlinkages help banking stability, should policies and regulations be designed to promote such cross-border interconnectedness? And to the extent that interlinkages are bad for stability, should policies and regulations aim to stop or, at least limit, the growth of such interlinkages?

We examine the above key question in two ways: First, we analyze it conceptually, using simulations. Second, we examine it empirically, based on a range of econometric approaches - parametric as well as nonparametric - that combine data on banking crises around the world with a comprehensive data set on cross-border banking linkages.

To preview the main results, our short answer to the above question is: it depends on the degree of interconnectedness. The relationship between the likelihood of a banking crisis in a country and the degree of integration of that country's banking sector into the global banking network is far from trivial. We find that in a country whose banking sector has relatively few linkages to other banking sectors, increased cross-border linkages tend to improve that system's stability, controlling for other factors. In other words, within a certain range, connections serve as a shock absorber. The system acts as a mutual insurance device, with disturbances dispersed and dissipated. Connectivity engenders robustness. Risk-sharing-diversificationprevails. But at some point-which we estimate to be at about the $95^{\text {th }}$ percentile of the distribution of countries in terms of interconnectedness-increases in crossborder links begin to have detrimental effects on domestic banking sector stability. At a still higher point, when a country's network of interlinkages becomes almost complete, ${ }^{3}$ the probability of a crisis goes down again.

One of the novel insights of our article is that it is important to distinguish whether the cross-border interlinkages stem primarily from banks' asset side or from their liability side. We introduce measures that distinguish those two types of interconnectedness (which we call "downstream" and "upstream" interconnectedness), and we find that the impact of changes in interconnectedness on banking system fragility are more significant for liability-side ("upstream") interconnectedness than for asset-side ("downstream") interconnectedness.

The article is structured as follows. Section 2 provides a discussion of the relationship between financial interconnectedness and instability, positioning the article as a bridge between the network analysis literature and the banking crisis literature. Section 3 presents the data, in particular the measures of interconnectedness and the measures of financial instability. Section 4 provides a simulation exercise. Section 5 describes the estimation procedures and presents the results of both parametric and nonparametric estimates. Section 6 concludes.

\footnotetext{
${ }^{3}$ A complete network is one in which all nodes are connected with each other.
} 


\section{Financial Stability Consequences of Increasing Interconnectedness}

Is greater connectedness to the outside world beneficial or detrimental to a country's banking system? Despite the obvious relevance of this question to national policymakers and regulators, and despite progress in understanding financial networks in recent years, the available literature does not provide a coherent set of answers.

Two main streams of literature are relevant for answering this question: the network analysis literature and the banking crisis literature. Each of these two streams provides useful insights. The network analysis literature focuses on the transmission of shocks within a network, but does not adequately model the underlying factors that make some banking systems more prone to crises than others in the first place. The banking crisis literature focuses on modeling banking crises in individual countries, but it does not take adequately into account the transmission of shocks via the global banking network.

Our article aims to bridge these two separate, but closely related, streams of literature. It offers an approach that takes into account both the differences in the underlying soundness of banking systems as well as their degree of connectedness with the broader banking network.

\subsection{Network Analysis}

Our article builds on the rapidly growing literature on financial networks. In particular, we build on the insight that financial interconnectedness has two opposing effects. On the one hand, linkages may act as channels to propagate shocks to the whole system, that is, they act as "shock transmitters". On the other hand, through these linkages, shocks can be shared and absorbed by others, that is, financial linkages may act as "shock absorbers."

In our article, the basic unit of analysis is a banking sector in a country, and the network being analyzed is the global banking network, i.e., the network of crossborder linkages among the various country-level banking sectors. This is different from much of the banking network literature, in which the basic unit of analysis is a single bank and the network is an interbank network, usually in a single country. While our approach has the drawback of not considering heterogeneity within national banking systems, the basic mechanics of shock transmission (via lending exposures) and absorption (via banks' net worth) are essentially the same, and we have the benefit of a global perspective.

Early theoretical literature on banking networks emphasized the benefits of interconnectedness for network stability. A key contribution in this regard was Allen and Gale (2000), who related banking system resilience to the completeness of the banking network. Specifically, based on an examination of a stylized four-bank network, they concluded that a "complete" network (one in which every bank is connected to all other banks) is more resilient than an "incomplete" network (one in which some banks are not connected to all other banks), due to both wider possibilities for risk sharing in complete networks and individual banks bearing a smaller share of the shock.

Similarly, Freixas et al. (2000) found that interbank connections contributed to the system's ability to withstand the insolvency of a particular bank because 
a certain percentage of losses from one bank are transferred to others through interbank agreements. This loss sharing increases the stability of the network but decreases its efficiency, as insolvent banks may continue to operate through implicit subsidies generated through interbank credit lines.

Nier et al. (2007) extended Allen and Gale's work by conducting simulations on a more complex network of banks with interlinked balance sheets. Interestingly, they identified a non-monotonic relationship between bank connectivity and contagious defaults. In particular, they found that the relationship between the number of defaults in a network and the likelihood of interbank exposure is M-shaped: at low levels of connectivity, an increase in interconnectedness raises the likelihood of contagion; at higher levels of connectivity, the resilience of the system improves, then declines, and then (in line with Allen and Gale's calculations) improves again as the network reaches completeness. The paper attributes this non-monotonic shape to the opposing forces of shock absorption and shock diffusion in financial networks.

The notion that complex financial networks are not only better at diversifying away idiosyncratic risk, but also more prone to propagating financial distress is a common theme in a number of recent papers on the subject (e.g., Battiston et al., 2010; Caballero and Simsek, 2009). An important part of the network analysis literature focuses on "cascading" effects in a network (May and Anderson, 1991; Watts, 2002; Kinney et al., 2005). The phenomenon of large but rare cascades triggered by relatively small shocks has been observed in areas as diverse as collective action, the diffusion of norms and innovations, cultural fads, and cascading failures in infrastructure and organizational networks. Watts (2002) reviews the literature and presents a possible explanation of this phenomenon in terms of a network of interacting agents whose decisions depend on the actions of their neighbors, based on a threshold rule. His model points out factors that make a network relatively more prone to the occurrence of large "cascades". In particular, when the network is highly connected, the size distribution of cascades becomes bimodal, implying a kind of instability that is correspondingly harder to anticipate. If the network nodes are characterized by very heterogeneous thresholds, the system is relatively more vulnerable to global cascades; on the other hand, if the nodes are very heterogeneous in terms of their degree of connectivity, the network is relatively less vulnerable. ${ }^{4}$

\subsection{Banking Crisis Literature}

A substantial body of literature exists on models of banking crises in individual countries. This includes a range of studies that attempt to identify, at a country level, early warning indicators of banking crises. The findings of this literature are far from conclusive, highlighting a need for further research. The following is a brief summary of the literature (for more, see, for example, Davis and Karim, 2008, and Čihák and Schaeck, 2010).

The so-called first-generation models hypothesize that an adverse macroeconomic environment adversely affects banks' borrowers, impacting the banks, and

\footnotetext{
${ }^{4}$ This is just a short summary of the relevant literature focusing on network analysis. Recent literature has seen growth of interest in new approaches, such as agent-based modeling, to approximate more complex behavior in payment systems (Somaräki et al., 2007). This is a promising area for future research.
} 
setting off bank runs that ultimately lead to bank closures (e.g., Miskhin, 1978); in contrast, the so-called second-generation models focus on depositor behavior and view banking crises as self-fulfilling prophecies or "sunspot" events reflecting sudden shifts in depositors' sentiment (e.g., Diamond and Dybvig, 1983). As regards empirical evidence, Gorton (1988) rejects the randomness of bank runs, finding (in long-term U.S. data) a systematic association between bank runs and recessions. Calomiris and Mason (1997), using data from the 1932 Chicago bank panic, cast some doubt on the contagion effects on other institutions that arise from deposit withdrawal: they do not find that such contagion effects lead to insolvency.

Third-generation models focus on the impact of boom and bust on banks' assets (e.g., Gavin and Hausman, 1996; Hardy and Pazarbaşioğlu, 1998; and Demirgüç-Kunt and Detragiache, 1998). These models point out that in economic booms, banks have incentives to engage in excessive lending against collateral, such as real estate and equities, which appreciates in value. This facilitates a lending boom and increasing leverage in the economy. A subsequent bust results in collapsing asset prices, leading banks to scale back their lending. Ultimately, this translates into an economic slowdown that increases borrower default rates. In contrast to the secondgeneration models, third-generation models focus on banks' assets rather than liabilities, and they use (lagged) macroeconomic variables as leading indicators.

Fourth-generation models extend the earlier literature by identifying features of the institutional environment that set the stage for the build-up of macroeconomic imbalances, which subsequently give rise to banking problems. These models accentuate the roles of rule of law and contract enforcement, protection of shareholder and creditor rights, sophistication of supervisory and regulatory frameworks, incentive schemes created by deposit insurance, and the socioeconomic environment (see, for example, Demirgüç-Kunt and Detragiache, 2005; and Buch and DeLong, 2008).

A rapidly growing body of literature has focused on market based indicators, such as the distance to default or the subordinated debt spread, as early warning indicators for banking problems on the micro level (e.g., Gropp, Vesala, and Vulpes, 2004). An advantage of this approach is that it builds upon forward-looking information contained in market prices. Its key disadvantage is its reliance on market prices derived from liquid markets, which limits its applicability when such markets do not exist.

The bottom line is that a clear agreement is yet to be reached in the literature on models and indicators for systemic banking problems. Moreover, importantly from the viewpoint of our article, this stream of literature tends to examine individual countries in isolation and has not been able to satisfactorily incorporate cross-border linkages and contagion within the global banking network. That is where, primarily, our article aims to contribute.

\section{Overview of Input Data}

\subsection{Measuring Interconnectedness}

We use network analysis to measure the degree to which a country's banking sector is connected to the rest of the global banking system. In the recent literature, network analysis has become a key tool for measuring the extent of interactions within a banking network. In our case, the banking network refers to the global 
architecture of cross-border financial relationships. We consider the global banking network as a set of bilateral claims (links) of different banking systems (nodes) on each other and calculate each system's interconnectedness (centrality) in the network using BIS locational banking statistics. ${ }^{5}$ The underlying idea of the analysis is to infer, from the pattern of cross-border linkages among banking sectors, the extent to which a banking sector of a jurisdiction is "central" in the international banking network (von Peter, 2007; Kubelec and Sá, 2010). ${ }^{6}$

We identified four possible measures of centrality, based on a review of the network analysis literature. The first one is "degree" centrality, which equals the sum of each banking system's links to other banking systems and serves as a basic measure of centrality. Its advantage is simplicity, but its main drawback is that it implicitly gives all links the same weight, irrespective of size. The second one is "alter-based" centrality (Neal, 2010 and 2011), a recursive measure that takes into account the relative importance of a banking system in the global network, as well as the relative importance of each banking system to which it is connected. In alterbased centrality, individual links are weighted by the partner country's centrality score and then summed. The third and fourth measures are, respectively, "alpha" and "beta" centrality (Bonacich and Lloyd, 2001; Bonacich, 1987), which are both derived from Bonacich's (1972) original eigenvector centrality measure. Similar to alter-based centrality, these two measures take into account the importance of a banking system and the importance of its partners; however, unlike alter-based centrality, they require certain additional assumptions to be met (Appendix I).

The subsequent analysis focuses on alter-based centrality as the preferred measure of centrality, given its ease of calculation and its intuitive nature. It is more comprehensive than degree centrality, since it takes into account partner jurisdictions' centrality, and it is more straightforward than the two Bonacich measures, given that the results for alter-based centrality do not require restrictive assumptions. ${ }^{7}$ Nevertheless, the four measures demonstrate a high degree of co-movement (Figure 1) and yield broadly similar results when used in regressions.

When examining the developments in alter-centrality over time (Figure 1), it is useful to note that this indicator's behavior has been far from uniform across countries. While some countries (e.g., Germany) have seen a relatively steady increase in alter-centrality over the sample period, others (e.g., Japan in the 1990s) have been going through a period of steady decline in alter-centrality, and yet others have seen several ups and downs.

\footnotetext{
${ }^{5}$ BIS locational statistics are based on the residency principle: data is collected on the positions of all banking offices located within each reporting jurisdiction, on a gross basis, regardless of nationality. This is consistent with balance of payments and external debt methodology and therefore the rest of the variables used in our analysis. The BIS data also include consolidated banking statistics, showing worldwide consolidated international financial claims of domestically owned banks (that is, the statistics are compiled using the nationality principle and interbank positions are netted out). Given that foreign subsidiaries are not wholly dependent on their parent bank and there exists the possibility of contagion from child to parent (and vice versa), and the fact that our banking crisis variable does not distinguish between countries' crises involving only domestically owned banks versus those involving domestic and foreign banks, we used the locational statistics, which essentially consider all banking offices as separate entities.

${ }^{6}$ For other recent contributions to network analysis in finance, see, for example, Nier et al. (2007), Hale (2011), and Minoiu and Reyes (2011).

${ }^{7}$ The data on the interconnectedness measure used in this article are available from the authors upon request.
} 
Figure 1 Movements in Centrality Measures for Selected Countries, 1985Q1-2009Q3
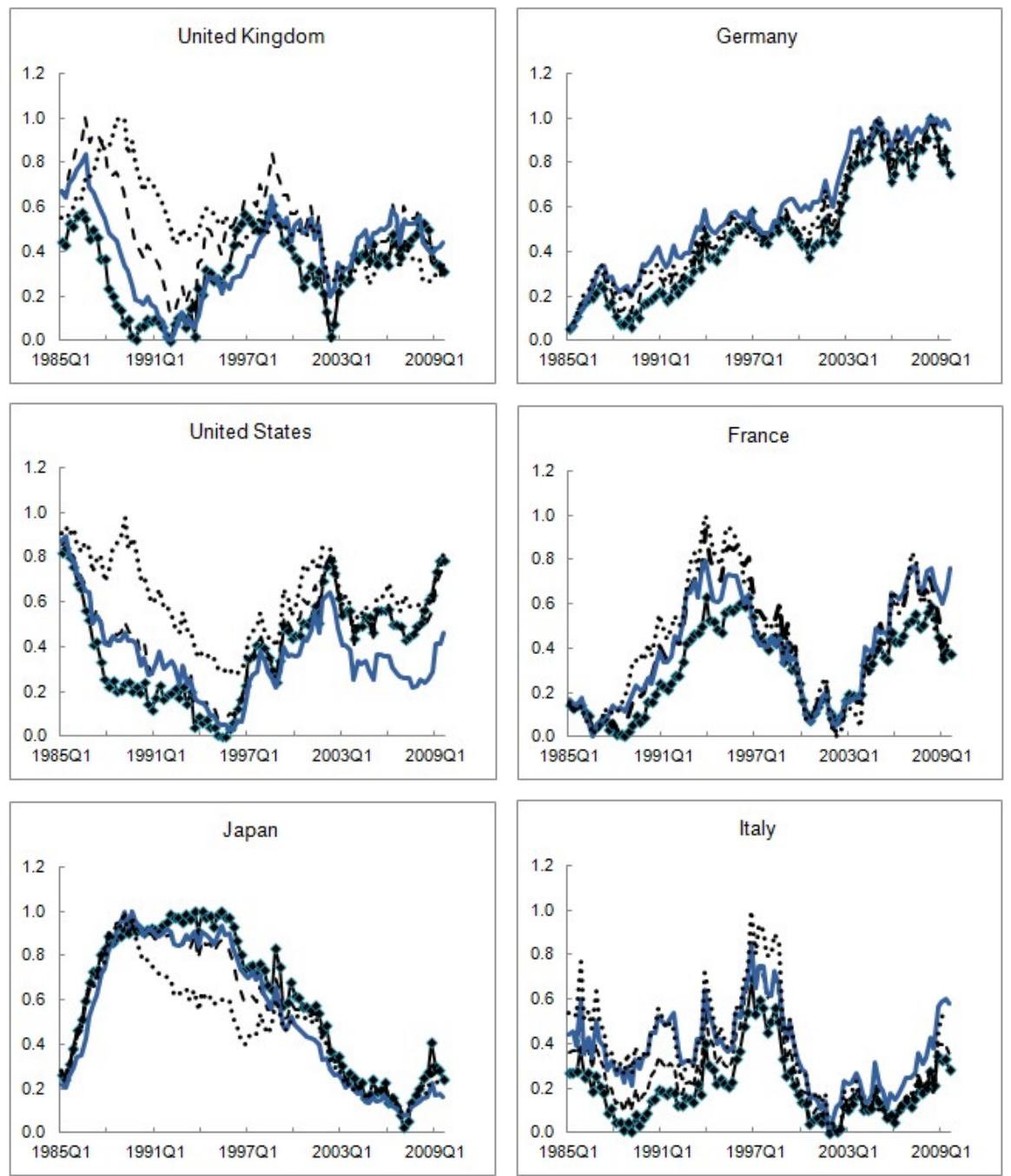

\section{...... Alter-based ——Alpha $\quad$ - - Beta $\longrightarrow$ Degree}

Note: Downstream measures, rescaled to $[0,1]$ for comparability across measures of different magnitudes. Sources: BIS locational banking statistics, authors' estimates.

One of the contributions of our article is that we explicitly distinguish two types of interconnectedness depending on whether the exposures come from the asset side (lending) or the liability side (borrowing). This distinction - a very important one for making appropriate policy decisions - means that we analyze a directed network. That is, links between banking systems provide information about the direction of the relationship rather than merely whether or not a relationship exists. ${ }^{8}$ We define and calculate: 
Figure 2 Banking Crises vs. Interconnectedness: A First Look
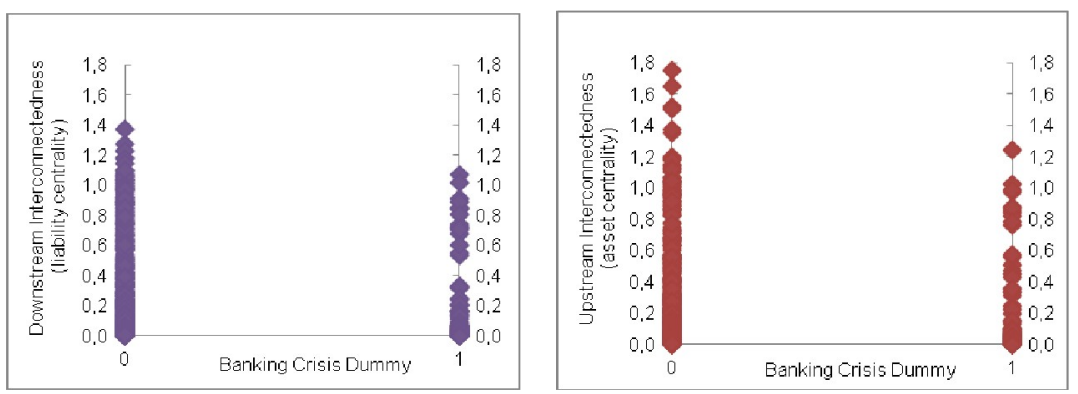

Sources: BIS locational banking statistics, authors' estimates.

- Downstream interconnectedness (or "asset centrality") as the recursive centrality measure of interconnectedness based on asset exposures for each banking system. The motivation for this comes from calling the asset (credit) exposure of creditor countries vis-à-vis borrowing countries a "downstream" exposure.

- Upstream interconnectedness (or "liability centrality") as the recursive centrality measure of interconnectedness based on liability exposures for each banking system. The motivation for this comes from calling the funding exposure of borrowing countries vis-à-vis credit countries an "upstream" exposure."

\subsection{Measuring Banking (In)stability}

We measure the (in)stability of a banking sector in a country as the probability of a banking crisis occurring in that country in a given year: the lower the crisis probability, the more stable the banking system. To derive this variable, we rely on the widely used database of banking crises by Caprio, Klingebiel, Laeven, and Noguera (2005), as updated by Laeven and Valencia (2008). The database covers the universe of $120+$ systemic banking crises around the globe since 1970. It is the most complete and most detailed database on banking crises to date. Based on the database, we define a banking crisis dummy variable, equal to 1 if there is a banking crisis in a country $i$ at time $t$ and 0 otherwise.

Scatter plots of the banking crisis variable against the two interconnectedness variables (Figure 2) suggest that there may be a relationship, and it is likely to be far from trivial. In particular, as regards downstream interconnectedness, there is an area in the middle (roughly between 0.3 and 0.6 ) characterized by low occurrence of banking crises, and there is also an area with high interconnectedness (roughly above 1.0) that has virtually no crisis observations. Similarly, the chart for upstream interconnectedness (liability centrality) shows an area with lower occurrence of banking

\footnotetext{
${ }^{8}$ In a similar vein, Minoiu and Reyes (2011) study directed networks using BIS locational data. Our upstream/downstream degree variables are similar to their in/out strength variables in that they both consider valued, rather than binary, network matrices. The main difference is that their analysis focuses on the dynamics and evolution of network metrics (flows rather than exposures), while our focus is on the impact of interconnectedness on financial stability. Appendix $I I$ has details on our calculations of centrality variables.

${ }^{9}$ The BIS banking statistics include banks' assets and liabilities vis-à-vis residents in foreign currencies, so exposures to other jurisdictions could be overestimated in some cases.
} 
crises in the region between 0.6 and 0.8 , and again an area with virtually no crisis observations above 1.0 .

\subsection{Other Data}

The global financial crisis experience has clearly illustrated that the relationship between banking interconnectedness and banking stability is affected by many other variables. While some jurisdictions with high degrees of interconnectedness have been hit severely during the crisis, other highly interconnected jurisdictions have managed to withstand this crisis (as well as the previous crises) remarkably well. It is therefore important to control for the other variables that also impact on banking stability in a country. Some of these variables have a separate effect on banking stability, while others work in interaction with interconnectedness.

We therefore compiled a set of other variables, building on datasets identified in the earlier literature. These variables cover the broader macroeconomic and institutional framework as well as features of the banking system such as its financial structure. A separate Excel file provides all the data compiled for the various control variables used in the analysis (together with a description of the data sources).

\section{Simulations}

As a prelude to the empirical analysis, and to illustrate the linkages between the network literature and the banking crisis literature, we ran a simulation exercise. The exercise examined, in a hypothetical network, what kind of relationship one can expect between interconnectedness (centrality) and banking sector stability. Appendix II describes the simulation framework used in this section.

Figure 3 shows simulation results based on a hypothetical network of 100 banking sectors (100 "countries"), run for 1,000 random realizations of the network and initial conditions. Each node was assigned a capitalization, and the matrix of interlinkages was filled with asset and liability values, determining the degrees of centrality for each of the nodes in each of the iterations, as described in the previous sub-section. The results shown in Figure 3 are for net worth set to equal 1 percent of total assets. The relationship between interconnectedness and crisis probability has the same (M) shape for other values of net worth, the difference being that the peaks of the "M" are lower (i.e., the crisis probability is lower) for higher values of net worth. ${ }^{10}$

Figure 3 illustrates the non-linear relationship between stability in a country's banking system and its interconnectedness with the global banking network. First, for very low levels of connectivity, an increase in connectivity increases the likelihood of a crisis, since connectivity increases the chance of shock transmission. For higher levels of connectivity, increases in connectivity first decrease and then increase the likelihood of a banking crisis. When connectivity is sufficiently high, further

\footnotetext{
${ }^{10}$ In addition to the random graph simulations shown in Figure 3, we ran simulations in which there are two groups of nodes: those with a high degree of connectivity ("money centers") and those with lower connectivity. This is similar to the "money center" networks examined by Sachs (2010), except that we are examining this in the context of the global country network rather than a single-country interbank market. Compared to the random graphs, crises tend to be more frequent in the "money center" networks, consistent with the findings of Sachs (2010). The general shape of the relationship between interconnectedness and stability remains as shown in Figure 3. The additional results are available upon request.
} 


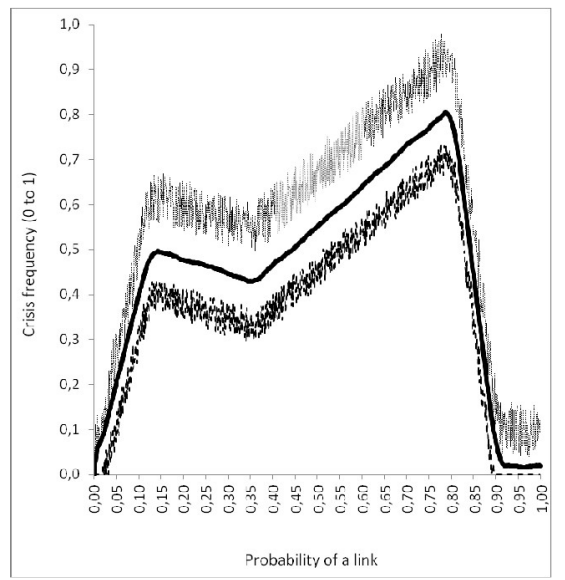

Notes: Results based on a hypothetical network of 100 banking sectors, run for 1,000 random realizations. The full/dotted/dashed lines denote, respectively, the median, maximum, and minimum crisis frequency observed in the simulations for each level of probability of a link. For details, see Appendix II.

Source: Authors' simulations.

increases in connectivity unambiguously decrease contagion as the shock absorption effect starts to dominate and the initial shock is spread over more and more banking systems, each able to withstand the shock received.

The simulation results in Figure 3 are consistent with the earlier literature. In particular, they are in line with the findings of Nier et al. (2007), who were the first to identify this kind of non-monotonic, M-shaped, relationship between bank connectivity and the number of contagious defaults in the network as a whole. The main difference (other than the fact that we analyze a network of banking sectors rather than a network of banks) is that we focus on the nodes of the network and examine the likelihood of a default (banking crisis) in each node of the network, instead of counting the (expected) number of defaults in the network as a whole. Another thing to note is that we are modeling a network that is heterogeneous (some nodes play a much more central role than others) and is far from "complete" (numerous links are missing in the network). ${ }^{11}$ This has important impacts on the observed relationship between interconnectedness and fragility: if the global banking network were close to "complete", the simulations suggest that we would probably see a drop in its fragility, as systems would become more resilient to shocks due to risk sharing. ${ }^{12}$

The simulation results also seem broadly consistent with the preliminary examination of the data. In particular:

- The data on banking crises and connectivity (Figure 2) suggest there is a range of middle values of connectivity (roughly between 0.3 and 0.6 for

\footnotetext{
${ }^{11}$ For the 33 jurisdictions that report comprehensive cross-border exposure data to the BIS, the network is 92 percent "complete" in the sense of Allen and Gale (2000), i.e., there are 92 percent of links out of all the theoretically possible links among those 33 jurisdictions. For the full sample of around 200 jurisdictions (i.e., taking into account all counterparties of the reporting jurisdictions), a precise determination is difficult due to missing values, but based on our estimates, the network is less than half "complete" (reflecting the much lower degree of network completeness outside the 33 reporting jurisdictions).
} 
downstream interconnectedness and between 0.6 and 0.8 for upstream interconnectedness) for which there is a relatively lower occurrence of banking crises. This is consistent with the finding from the simulation that there is a middle area where the crisis probability first goes down and then goes up as the probability of links goes up.

- The raw empirical data (Figure 2) also suggest that when connectedness reaches a certain point (roughly 1.0 for both downstream and upstream interconnectedness), the frequency of crisis observations drops off substantially (very close to zero). Similarly, the simulations (Figure 3) show that as the probability of a link reaches a point of high interconnectedness, the crisis probability drops off precipitously (to a number very close to zero).

One part where the simulations may seem, on a quick look, to differ from the empirical data, is the area of very low interconnectedness. There, the simulation model (Figure 4) predicts a low crisis frequency, while the empirical data (Figure 2) show a relatively high frequency. However, it needs to be understood that the simulations in Figure 2 focus on contagious defaults and not on the other factors that may make a crisis in a country more or less likely. It is possible that the countries whose banking systems have a relatively low degree of connectivity to the global banking network nonetheless have other features that make their systems prone to (domestically induced) banking crises. To examine this in more detail, we turn to the empirical analysis, which aims to distinguish more precisely the cross-border factors (interconnectedness) from the domestic factors of banking sector fragility.

\section{Estimating a Financial Stability Model}

Empirically, we examine the linkage between banking interconnectedness and domestic banking sector stability using two main complementary approaches: a parametric estimation (probit model) and a nonparametric estimation (threshold approach).

\subsection{Parametric Estimation (Probit Model)}

We examine the relationship between cross-border interconnectedness and the probability of a banking crisis in a country using a multivariate probit model for a panel dataset of 189 banking systems in 1977-2009. The probability of observing a banking crisis in country $i$ in year $t$ is modeled as a function of interconnectedness, a set of macroeconomic and other control variables, as well as interactions between interconnectedness and other variables. The estimated log-likelihood function is

$$
L n L=\sum_{t=1 \ldots T} \sum_{i=1 \ldots n}\left\{P(i, t) \ln \left[F\left(\beta^{\prime} X(i, t)\right)\right]+(1-P(i, t)) \ln \left[1-F\left(\beta^{\prime} X(i, t)\right)\right]\right\}
$$

where $P(i, t)$ is the banking crisis dummy variable (equal to 1 if there is a crisis, and 0 otherwise), $\beta$ is the vector of coefficients, and $X$ is the vector of explanatory

${ }^{12}$ Allen and Gale (2000) and the related literature emphasize that a "complete" financial network (one with full links among all banking sectors around the world) is more resilient to shocks than an "incomplete" network. However, Allen and Gale (2000) focus on a highly stylized small system with four individual banks. In our simulation, we had a global banking network of 100 banking sectors that were interconnected but did not form a "complete" network. 
Table 1 Parametric Estimates (Probit Model)

\begin{tabular}{|c|c|c|c|c|c|c|}
\hline \multicolumn{7}{|c|}{ Dependent variable: Banking crisis ${ }^{a}$} \\
\hline Variables $^{\mathrm{b}}$ & (1) & (2) & (3) & (4) & (5) & (6) \\
\hline Constant & $\begin{array}{l}-2.671^{* * *} \\
(0.305)\end{array}$ & $\begin{array}{l}-2.390^{* * *} \\
(0.242)\end{array}$ & $\begin{array}{l}-2.5700^{* * *} \\
(0.431)\end{array}$ & $\begin{array}{l}-1.411^{* * *} \\
(0.381)\end{array}$ & $\begin{array}{l}-2.966^{* * *} \\
(0.338)\end{array}$ & $\begin{array}{l}-2.733^{* * *} \\
(0.313)\end{array}$ \\
\hline \multicolumn{7}{|l|}{ Control variables: } \\
\hline Banking crisis $t-1$ & & $\begin{array}{l}1.808^{* \star *} \\
(0.139)\end{array}$ & $\begin{array}{l}1.857^{* * *} \\
(0.217)\end{array}$ & $\begin{array}{l}1.661^{\star \star *} \\
(0.098)\end{array}$ & & \\
\hline M2/reserves & $\begin{array}{l}0.003^{* *} \\
(0.002)\end{array}$ & $\begin{array}{r}0.003 \text { * } \\
(0.001)\end{array}$ & $\begin{array}{l}0.004^{* *} \\
(0.002)\end{array}$ & $\begin{array}{r}0.002 \text { * } \\
(0.001)\end{array}$ & $\begin{array}{r}0.000 \\
(0.002)\end{array}$ & $\begin{array}{l}0.003^{* *} \\
(0.002)\end{array}$ \\
\hline Depreciation & $\begin{array}{l}0.013^{* * *} \\
(0.005)\end{array}$ & $\begin{array}{r}0.006 \\
(0.004)\end{array}$ & $\begin{array}{r}-0.001 \\
(0.008)\end{array}$ & $\begin{array}{l}0.009^{* * *} \\
(0.002)\end{array}$ & $\begin{array}{l}0.014^{* * *} \\
(0.005)\end{array}$ & $\begin{array}{l}0.013^{* * *} \\
(0.005)\end{array}$ \\
\hline $\begin{array}{l}\text { Growth of private } \\
\text { credit over GDP } t-1\end{array}$ & $\begin{array}{l}1.143^{* \star *} \\
(0.291)\end{array}$ & $\begin{array}{l}0.692^{* * *} \\
(0.192)\end{array}$ & $\begin{array}{l}0.681^{* * *} \\
(0.248)\end{array}$ & $\begin{array}{l}0.403^{* *} \\
(0.159)\end{array}$ & $\begin{array}{l}1.447^{* * *} \\
(0.337)\end{array}$ & $\begin{array}{l}1.1966^{* * *} \\
(0.304)\end{array}$ \\
\hline GDP growth & $\begin{array}{l}-0.090^{* * *} \\
(0.018)\end{array}$ & $\begin{array}{l}-0.097^{* \star *} \\
(0.018)\end{array}$ & $\begin{array}{l}-0.126 \text { *** } \\
(0.030)\end{array}$ & $\begin{array}{l}-0.0611^{\star * *} \\
(0.010)\end{array}$ & $\begin{array}{l}-0.074^{* * *} \\
(0.019)\end{array}$ & $\begin{array}{l}-0.089^{* * *} \\
(0.018)\end{array}$ \\
\hline Real interest rate & $\begin{array}{r}-0.005 \\
(0.010)\end{array}$ & $\begin{array}{r}0.007 \\
(0.009)\end{array}$ & $\begin{array}{r}0.011 \\
(0.015)\end{array}$ & $\begin{array}{r}0.003 \\
(0.004)\end{array}$ & $\begin{array}{r}-0.004 \\
(0.011)\end{array}$ & $\begin{array}{l}-0.005 \\
(0.010)\end{array}$ \\
\hline Inflation & $\begin{array}{l}0.018^{* * *} \\
(0.005)\end{array}$ & $\begin{array}{l}0.013^{* * *} \\
(0.004)\end{array}$ & $\begin{array}{r}0.014 \\
(0.008)\end{array}$ & $\begin{array}{r}0.000 * \\
(0.000)\end{array}$ & $\begin{array}{l}0.027^{* * *} \\
(0.007)\end{array}$ & $\begin{array}{l}0.017^{* * *} \\
(0.005)\end{array}$ \\
\hline Cost-to-income ratio & $\begin{array}{l}0.986 \text { *** } \\
(0.256)\end{array}$ & $\begin{array}{l}0.651^{* * *} \\
(0.244)\end{array}$ & $\begin{array}{c}0.62 \text { * } \\
(.356)\end{array}$ & & $\begin{array}{l}1.054^{* * *} \\
(0.270)\end{array}$ & $\begin{array}{l}0.991^{* * *} \\
(0.259)\end{array}$ \\
\hline Stock volatility & & & $\begin{array}{r}0,010 \\
(0.007)\end{array}$ & & & \\
\hline $\begin{array}{l}\text { Interconnectedness } \\
\text { variables: }\end{array}$ & & & & & & \\
\hline $\begin{array}{l}\text { Upstream } \\
\text { interconnectedness } t-1\end{array}$ & $\begin{array}{l}-3.324^{* *} \\
(1.410)\end{array}$ & $\begin{array}{l}-2.072 * \\
(1.070)\end{array}$ & $\begin{array}{l}-2.115 * \\
(1.141)\end{array}$ & $\begin{array}{l}-1.591 * * \\
(0.796)\end{array}$ & $\begin{array}{r}0.311 \\
(3.288)\end{array}$ & \\
\hline $\begin{array}{l}\text { Upstream } \\
\text { interconnectedness } t-1\end{array}$ & $\begin{array}{l}2.816^{* *} \\
(1.344)\end{array}$ & $\begin{array}{l}1.940 * \\
(1.036)\end{array}$ & $\begin{array}{l}1.961 * \\
(1.082)\end{array}$ & $\begin{array}{l}1.374^{* *} \\
(0.686)\end{array}$ & $\begin{array}{l}3.164 \text { * } \\
(1.917)\end{array}$ & \\
\hline $\begin{array}{l}\text { Downstream } \\
\text { interconnectedness } t-1\end{array}$ & & & & & & $\begin{array}{l}-1.559 \\
(1.386)\end{array}$ \\
\hline $\begin{array}{l}\text { Downstream } \\
\text { interconnectedness } t-1\end{array}$ & & & & & & $\begin{array}{r}0.172 \\
(1.652)\end{array}$ \\
\hline Interaction terms: & & & & & & \\
\hline $\begin{array}{l}\text { Upstream } \\
\text { interconnectedness } X \\
\text { M2/reserves }\end{array}$ & & & & & $\begin{array}{l}0.092 \text { ** } \\
(0.036)\end{array}$ & \\
\hline
\end{tabular}

continued 
Dependent variable: Banking crisis (continued)

\begin{tabular}{|c|c|c|c|c|c|c|}
\hline & (1) & (2) & (3) & (4) & (5) & (6) \\
\hline $\begin{array}{l}\text { Upstream } \\
\text { interconnectedness } X\end{array}$ & & & & & -0.115 & \\
\hline Depreciation & & & & & $(0.076)$ & \\
\hline $\begin{array}{l}\text { Upstream } \\
\text { interconnectedness } X\end{array}$ & & & & & -3.536 & \\
\hline $\begin{array}{l}\text { Growth of private } \\
\text { credit over GDP }{ }_{t-1}\end{array}$ & & & & & (2.787) & \\
\hline $\begin{array}{l}\text { Upstream } \\
\text { interconnectedness } X\end{array}$ & & & & & $-1.201 * *$ & \\
\hline GDP growth & & & & & $(0.475)$ & \\
\hline $\begin{array}{l}\text { Upstream } \\
\text { interconnectedness } X\end{array}$ & & & & & 0.423 & \\
\hline Real interest rate & & & & & $(0.265)$ & \\
\hline $\begin{array}{l}\text { Upstream } \\
\text { interconnectedness } X\end{array}$ & & & & & -0.355 * & \\
\hline Inflation & & & & & $(0.188)$ & \\
\hline $\begin{array}{l}\text { Upstream } \\
\text { interconnectedness } X\end{array}$ & & & & & -2.714 & \\
\hline Cost-to-income ratio & & & & & (3.902) & \\
\hline Time dummies & Not sig. & Not sig. & Not sig. & Yes & Not sig. & Not sig. \\
\hline No. of Observations & 1354 & 1354 & 681 & 2320 & 1354 & 1354 \\
\hline Model $x^{2}$ & 117.71 *** & $258.43^{* * *}$ & 135.12 *** & 429.19 *** & $117.44^{* \star *}$ & $115.19^{* * *}$ \\
\hline Log Likelihood & -330.859 & -253.270 & -125.545 & -559.876 & -317.057 & -331.37 \\
\hline
\end{tabular}

Notes: ${ }^{a}$ As defined in Laeven and Valencia (2010). The dependent variable takes a value one if there is a banking crisis and the value zero otherwise.

b ${ }^{*},{ }^{* *},{ }^{* *}$ correspond to the 10,5 , and 1 percent significance levels, respectively. We estimate a random-effects probit model. Standard errors are given in parenthesis.

variables. As regards interconnectedness, we tried to include it not only as a linear term, but also as a quadratic and cubic term, to examine the possible non-linearity suggested by the simulations.

The regression results (Table 1$)^{13}$ suggest that (i) increases in a banking sector's degree of interconnectedness with the global banking network tend to be associated with reductions in the probability of a crisis in that banking sector; (ii) the reduction in crisis probability gets smaller as interconnectedness goes up, keeping other things constant; (iii) when the banking sector's interconnectedness reaches a certain point, further increases in interconnectedness actually start increasing the probability of crisis in the banking sector; and (iv) at very high degrees of interconnectedness, the crisis probability declines again.

These key findings are rather robust across a range of specifications. To demonstrate the robustness of the results, Table 1 includes regressions with different sets of control variables, and it includes regressions both with interactions between interconnectedness and other variables, as well as without the interactive terms.

${ }^{13}$ Table 1 shows the results with the cubic term of interconnectedness. Similar results are obtained with a quadratic term. 
Regression (1) is the basic specification. Regression (2) adds the lagged value of the banking crisis dummy variable. ${ }^{14}$ Regression (3) adds stock price volatility as an additional control variable. Regression (4) adds time dummies while dropping the cost-to-income ratio and stock price volatility. ${ }^{15}$ Regression (5) gives the interactions without the lagged banking crisis or stock volatility. Finally, regression (6) uses downstream interconnectedness, which is not significant when the cubic term is included.

We also examine a specification that takes into account banking sector capitalization (approximated by the capital-to-asset ratio and, alternatively, by the regulatory capital-to-risk-weighted assets ratio). Based on the simulations reported in section 4, we expect higher capitalization to be associated with lower crisis probability. Obtaining consistent and long time series on bank capitalization is more challenging than for most of the other variables, resulting in a substantial reduction of the number of observations. For this reason, and to save space, we do not show these results in Table 1. Nonetheless, these additional regression results, which are available upon request, suggest that bank capitalization is negatively significant (consistent with the simulations that link higher bank capitalization to lower crisis probability) and upstream interconnectedness squared is positively significant (consistent with the empirical results shown in Table 1).

Additionally, to capture the differences between advanced and other economies, we considered including a 0/1 dummy variable for advanced economies (World Economic Outlook definition). The variable is not included in Table 1 given collinearity with the level of interconnectedness term and growth of private credit over GDP, but its inclusion without one or both terms yields similar levels of significance of the cubic term of interconnectedness.

Overall, these probit estimates are consistent with the simulation findings of an $M$-shaped curve, illustrating a non-linear relationship between stability in a country's banking system and the interconnectedness of that system. Specifically, the significant positive sign of the cubic term for upstream interconnectedness implies that for banking systems that are not very connected to the global banking network, increases in interconnectedness are at first associated with a reduced probability of a banking sector crisis. Once the degree of interconnectedness reaches a certain value, further increases in interconnectedness are not associated with improvements in financial stability and can in fact mean increased fragility. ${ }^{16}$ However, at yet another point, when the banking system becomes highly interconnected, the crisis probability begins to decline again.

From the parameter estimates in Table 1, one can calculate the points at which the effect of increases in interconnectedness on banking crisis probability turns signs. Let us focus here on the point where the relationship between interconnectedness and crisis probability switches signs for the first time, i.e., where it reaches its first local minimum. Solving for this minimum, using the point estimates from specification (5)

\footnotetext{
${ }^{14}$ This follows the study by Wooldridge (2005) showing that standard random-effects probit estimates can be used on dynamic panel datasets.

${ }^{15}$ When the cost-to-income ratio is excluded, the number of observations increases by about 1,000 . With the addition of time dummies, the estimates become highly significant.

${ }^{16}$ As with any similar probit estimations, we are careful not to interpret our results in a causal way.
} 
in Table 1, and keeping the other significant variables at their sample average values, we find that the minimum is reached when upstream interconnectedness equals $0.37 .{ }^{17}$ This corresponds to the $95^{\text {th }}$ percentile of the distribution of upstream interconnectedness. In other words, 95 percent of the interconnectedness observations in our sample are in the downward-sloping portion of the relationship, where interconnectedness reduces crisis probability. For the remaining 5 percent (those with upstream interconnectedness above 0.37), the relationship between interconnectedness and crisis probability is more complex: it is upward-sloping at first, only to become downward-sloping again. Indeed, these upper 5 percent of observations in terms of interconnectedness include some of the advanced economies whose large and highly interconnected banking sectors have been substantially affected during the recent financial crisis, while also including some highly interconnected banking sectors that have been relatively unharmed.

The probit estimates highlight that the probability of banking crisis is affected not only by interconnectedness, but also by other factors, some of which also interact with the interconnectedness variable, as shown in estimate (5) in Table 1. The 0.37 "critical point" was calculated at the sample average, so for instance for an economy that consistently shows rates of economic growth that are above our sample average, increasing interconnectedness even above 0.37 would still help reduce the probability of banking crisis. ${ }^{18}$ In other words, for this economy, the "critical point" would occur at a higher level of interconnectedness than $0.37 .{ }^{19}$

Interestingly, we obtain different results for upstream and downstream interconnectedness - a novel distinction that has not yet been examined in the literature. In particular, we find that the "dark side" of interconnectedness (i.e., the negative effects that dominate when a certain level of interconnectedness is exceeded) exists for the upstream measure of interconnectedness, while the same cannot be said for the downstream measure. In other words, increasing interconnectedness on the liability (borrowing) side is more likely to become detrimental to banking stability than increasing interconnectedness on the asset (creditor) side. Therefore, financial turmoil originating in creditor countries and "flowing upstream" via borrowing countries' funding channels could be more devastating than financial turmoil originating in borrowing countries and "flowing downstream" to the creditors.

Finally, the probit estimates also provide useful information on the impact of other variables that also need to be taken into account when considering the relationship between interconnectedness and banking sector stability. The control variables have the expected signs. For instance, the lagged ratio of growth of private sector credit to GDP is significant and exhibits a positive sign. This is consistent with the early warning literature suggesting that lending booms tend to lead to bank-

\footnotetext{
${ }^{17}$ This calculation is meaningful only for upstream interconnectedness, given that the point estimate for downstream interconnectedness is insignificant.

${ }^{18}$ This is because the interaction of economic growth with interconnectedness reduces the probability of banking crisis, as indicated in estimate (5) in Table 1.

${ }^{19}$ Note that we are using here the alter-based centrality measures, the theoretical maximum for which is 25 . In our sample, the maximum observed value is 1.75 for the liability measure and 1.37 for the asset measure. Note also that the maximum observed values declined somewhat in the 1990s and 2000s as the global banking network became bigger and more multi-nodal (rendering individual nodes less "central" to the network).
} 
ing crises. The results also show that real GDP growth is negatively related to the occurrence of a banking crisis, which highlights the importance of the state of the real economy in determining the health of banks. As expected, stock market volatility is also positively related to banking crises, but it is not statistically significant. A higher cost-to-income ratio, which could be interpreted as reflecting the banking system's inefficiency, is associated with a significantly higher probability of a banking crisis. The lag of banking crisis is significant, highlighting the persistence of crises. The ratio of the monetary aggregate M2 to foreign exchange reserves is used as a proxy for sudden capital outflows, to control for the relationship between these outflows and banking sector problems in countries with fixed exchange rates.

\subsection{Nonparametric Estimation (Threshold Approach)}

To cross-check and complement the parametric (probit) estimates, we also estimated nonparametric models aimed at signal extraction. As with the parametric exercise, the purpose of the nonparametric estimation is to examine the impact of cross-border interconnectedness on the likelihood of a banking crisis occurring in a country. The following section provides only a short introduction to the threshold approach; for a more in-depth exposition, see in particular Kaminsky, Lizondo, and Reinhart (1998) and Alessi and Detken (2009).

Nonparametric estimation (threshold approach) does not impose distributional assumptions upon the data, and the inferences drawn from such estimation may therefore be considered more robust than parametric models, such as probit models. An additional benefit is the ability of the nonparametric tests to illustrate the classification accuracy of the relevant variables over different threshold levels. Their main drawbacks include computational difficulties, especially when analyzing interaction among numerous indicators with potentially multitudes of possible thresholds.

The nonparametric approach aims to identify a combination of threshold values for interconnectedness and other variables (capitalization, economic growth, etc. - the same ones as in the parametric exercise) such that they enable us to identify banking crisis situations (i.e., observations for which the banking crisis dummy equals 1) as accurately as possible. Of course, the definition of "as accurately as possible" needs to take into account both Type I errors (false alarms) and Type II errors (missed crises), with the latter being much more costly. Our nonparametric algorithm therefore seeks to minimize the number of Type II errors, but it is a constrained minimization. Otherwise, without constraints, the result of the minimization would be a set of thresholds that would identify all or most of our sample as potential crisis observations (i.e., we would have very large Type I errors).

The nonparametric algorithm therefore solves for a combination of thresholds such that it minimizes Type II errors (missed banking crises) subject to the constraint that the ratio of predicted banking crises to total observations is not larger than the actual frequency of crisis observations. The percentage of actual crisis observations in our sample is about 7.4 percent. Therefore, our algorithm seeks to identify a set of thresholds (on interconnectedness and other variables) such that as many of the actual crises (i.e., observations for which the banking crisis dummy equals 1) are 
Figure 4 Nonparametric Analysis Results

(a) Upstream Interconnectedness

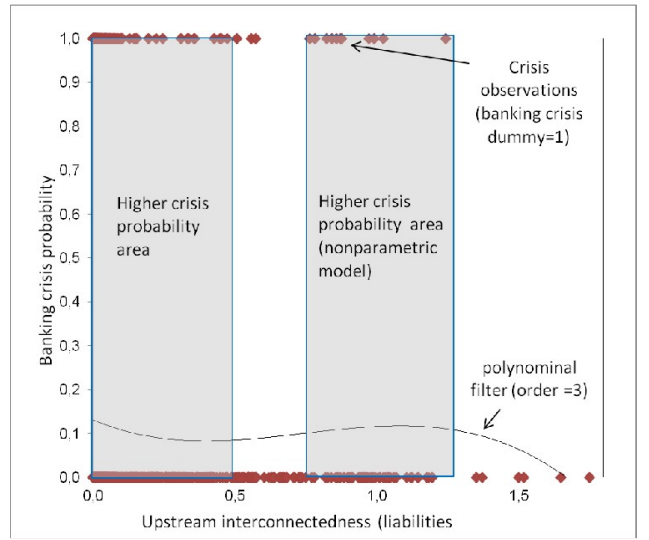

(b) Downstream Interconnectedness

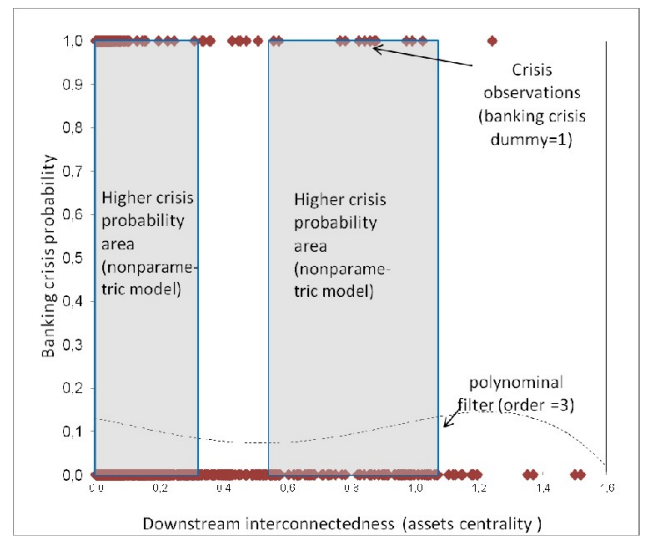

Notes: The higher- and lower-crisis probability areas were determined by the nonparametric method described in section $\mathrm{V}$. The polynomial filter of the $3^{\text {rd }}$ order is a simpler version of the multinomial parametric estimates presented in Section IV, and is added here for illustration.

Sources: BIS locational banking statistics, authors' estimates.

"predicted" (i.e., all the thresholds are breached for those observations) as possible, but the number of such predicted crises is not larger than 7.4 percent of all the observations. We use a numerical algorithm that examines various combinations of thresholds in a step-wise fashion and for each calculates the share of "predicted" crises and the number of Type II errors.

The dataset used in the nonparametric analysis is the same as used in the parametric estimates. It is a pooled dataset on 189 banking systems in 1977-2009. We focused on pairs and triplets of variables, with one or two thresholds on each variable. This reflects the computational complexities (as well as the challenges of visually presenting the results in more than two- and definitely in more than threedimensions). 
Overall, the results of the nonparametric estimates are consistent with the simulations and with the earlier findings from the parametric (probit) estimates. In particular, Figure 4(a) shows, for upstream interconnectedness, that the optimum results in terms of the noise/signal ratio (as described above) are achieved for a combination of thresholds that identifies two "higher crisis probability" areas (one for interconnectedness roughly below 0.5 and one between 0.8 and 1.3) and two "low crisis probability" areas (one roughly between 0.5 and 0.8 and one above 1.3). ${ }^{20}$ Figure 4(b) shows the results for downstream interconnectedness, which are qualitatively broadly similar, but statistically much weaker.

\section{Conclusion}

When a country's banking system becomes more linked to the global banking network, does it get more or less stable? Our answer is: it depends on the degree of interconnectedness. Based on model simulations as well as an econometric estimation based on a comprehensive global dataset, we find that in banking systems that are not very connected to the global banking network, increases in interconnectedness are associated with a reduced probability of a banking sector crisis. Once the degree of interconnectedness reaches a certain value, further increases in interconnectedness do not improve financial stability and can in fact increase fragility. When the interconnectedness reaches close to a complete network, it starts reducing the likelihood of crisis again.

The "dark side" of interconnectedness (i.e., the negative effects that dominate when a certain level of interconnectedness is exceeded) is stronger for the upstream measure of interconnectedness. In other words, increasing interconnectedness on the liability (borrowing) side is more likely to become detrimental to banking stability than increasing interconnectedness on the asset (creditor) side. Therefore, financial turmoil originating in creditor countries and flowing upstream via borrowing countries' funding channels could be more devastating for financial stability.

Our findings are potentially relevant for policymakers and financial sector regulators. Our calculations suggest that up to a point, it may be beneficial for policies and regulations (including supervision) to support greater interlinkages between the domestic banking sector and foreign banks. Above that threshold, the benefits of greater interlinkages are less clear; in fact, our calculations suggest that further growth in interlinkages can at that point become detrimental to banking stability. The calculations also indicate that the potential negative effects of interconnectedness can be compensated for by other factors (which can also be influenced by policies), such as greater capitalization of the banking sector. Of course, practical implementation of these policies is not always obvious. For example, improvements in coordination among domestic and foreign banking supervisors should in principle help in promoting sound cross-border linkages among banks. However, in practice, well-intended attempts to improve cross-border supervisory coordination (e.g., by signing various "memoranda of understanding" and setting up "supervisory colleges") are often hampered by conflicting incentives of the various supervisors, as docu-

\footnotetext{
${ }^{20}$ As a side note, the comparison with a simple polynomial filter (order 3) illustrates that the nonparametric approach emphasizes reducing Type II errors (missed crises) - it includes among the "higher probability" even areas that, based on the polynomial filter, could be identified as medium-probability.
} 
mented for example in Čihák and Decressin (2007) and D’Hulster (2011). A fuller examination of the policies influencing financial interlinkages and their impact on financial stability goes beyond the scope of this article but is an important topic for further research.

\section{APPENDIX I}

\section{Measuring Interconnectedness: A Primer}

With the increasing interconnectedness of the global financial network and the related spillover effects, recognizing and defining the importance of each jurisdiction within the network based on its relationships with other jurisdictions is becoming increasingly important. Borrowing methodology familiar to sociology, biology, and other disciplines where network analysis plays an important role, we explore several measures of interconnectedness (centrality) for the global banking network.

The most basic of these measures, and the easiest to understand, is degree centrality. It is defined as the sum of each network member's (node's) connections with all other members (nodes) of the network. That is,

$$
a_{i}=\sum_{j} a_{i j}
$$

where $a_{i j}$ are elements of matrix $\mathbf{A}$, representing relationships between each node. For binary matrices (elements equal to 1 if a connection exists, 0 otherwise), the degree will merely be the number of existing connections between node $i$ and all other nodes, while for valued matrices, the degree will be the summed values of all existing connections.

A more complex measure of centrality is Bonacich's eigenvector centrality. Since its introduction in 1972, it has been widely used to gauge the importance of individual nodes within a network. The basic premise underlying this measure is that a node's importance within the network is recursively related to the importance of the nodes to which it is connected. Where $\mathbf{A}$ is a matrix of relationships between nodes, this can be expressed as

$$
x_{i}=a_{1 i} x_{1}+a_{2 i} x_{2}+\ldots+a_{n i} x_{n}
$$

with $a_{i j}$ defining the relationship that exists between nodes $i$ and $j$, and $x$ representing the centrality score of each node. Since it is unlikely that this system of equations has a nonzero solution, it can be generalized to assume that each node's centrality score is proportional to, rather than equal to, the weighted sum of the other nodes' scores:

$$
\lambda x_{i}=a_{1 i} x_{1}+a_{2 i} x_{2}+\ldots+a_{n i} x_{n}
$$

In matrix notation this is expressed as

$$
\lambda \mathbf{x}=\mathbf{A}^{\prime} \mathbf{x}
$$

where $\lambda$ is a scalar and an eigenvalue (characteristic root) of matrix $\mathbf{A}$, while $\mathbf{x}$ is an eigenvector (characteristic vector) of matrix $\mathbf{A}$. Each element of the eigenvector, 
related to each node in the network, provides a relative measure of each node's importance within the network.

In 1987, Bonacich introduced a related measure, ${ }^{21} \hat{x}$ or beta centrality, which allows for variation in the degree and direction of dependence of each node's score on other nodes:

$$
\hat{x}_{i}=\sum_{j}\left(\alpha+\beta \hat{x}_{j}\right) \mathrm{A}_{i j}
$$

In matrix notation, this can be written as:

$$
\hat{x}=\alpha(I-\beta \mathbf{A})^{-1} \mathbf{A} 1
$$

Again, $\mathbf{A}$ is a matrix representing the relationships existing between each node of the network; $\beta$ reflects the degree to which a node's score is a function of other nodes' scores. Small values of $\beta$ put more emphasis on direct connections between nodes, while larger values take into account more distant connections. That is, small values emphasize the local structure, while larger values put more emphasis on the network as a whole. It can be seen from equation (1.6) that as $\beta$ approaches $0, \hat{x}$ approaches the degree measure (i.e., merely the sum of each node's immediate connections to other nodes). While this measure allows for more flexibility in defining the relationship between nodes, there are certain assumptions that must be met for meaningful results. More specifically, while not essential for equation (1.6), Bonacich's measure is interpreted under the assumption that $\beta$ does not exceed the value of the absolute value of the inverse of the largest eigenvalue of matrix $\mathbf{A}$. That is $\beta<\left|\frac{1}{\lambda}\right|$. When this condition is met, $\hat{x}$ is an infinite sum:

$$
\hat{x}=\alpha \sum_{k=0}^{\infty} \beta^{k} \mathbf{A}^{k+1} 1=\alpha\left(\mathbf{A} 1+\beta \mathbf{A}^{2} 1+\beta^{2} \mathbf{A}^{3} 1+\ldots\right)
$$

However, if this condition is not met, equation (1.6) does not converge and $\hat{x}$ loses some of its interpretation.

A more specific form of beta centrality, known as alpha centrality, has also been introduced. In matrix notation this measure can be expressed as

$$
\bar{x}=\left(I-\alpha \mathbf{A}^{\prime}\right)^{-1} e
$$

where $\bar{x}$ is the centrality score, $\alpha$ reflects the relative importance of endogenous versus exogenous factors in the determination of centrality, and $e$ represents exogenous factors. Since this measure is almost identical to beta centrality, and also relies upon the above-mentioned assumption being met, it yields similar results.

Finally, we consider a newer measure of centrality introduced by Neal (2010), known as alter-based centrality. This measure is also a recursive measure of centrality, but rather than relying upon the calculation of eigenvalues and eigenvectors or certain assumptions being met, alter-based centrality is calculated for node $i$ as the sum of each node $j$ 's degree centrality weighted by the connection between $i$ and $j$ :

${ }^{21}$ Bonacich's 1987 measure is related to Katz's 1953 measure. See Bonacich (1987) for details. 


$$
\tilde{x}_{i}=\sum_{j} a_{i j} a_{j}
$$

where $i \neq j, a_{i j}$ is the relationship that exists between nodes $i$ and $j$, and $a_{j}$ is node $j$ 's degree centrality. This measure therefore takes into account the relative importance of nodes to which $i$ is connected and the strength of the connection between nodes; however, it does not rely upon eigenvectors, does not require selection of a beta or alpha value, and does not require any assumptions to be met, making it more intuitive and mathematically transparent than its predecessors. While the measures are not exactly the same, they generally tend to show a high degree of similarity (see, for example, Figure 1).

\section{Data and Network Matrices}

Interbank network matrices for each year are constructed using year-end stock data from the Bank for International Settlements' quarterly locational banking statistics, covering the period 1977Q4 through 2009Q3. Data are reported by 33 jurisdictions: ${ }^{.2}$

\begin{tabular}{llll}
\hline Australia & Finland & Luxembourg & Turkey \\
Austria & France & Malaysia & United Kingdom \\
Belgium & Germany & Mexico & United States \\
Brazil & Greece & Netherlands & \\
Canada & Guernsey & Norway & \\
Cayman Islands & India & Portugal & \\
Chile & Ireland & South Korea \\
Chinese Taipei & Italy & Spain & \\
Cyprus & Japan & Sweden & \\
Denmark & Jersey & Switzerland & \\
\hline
\end{tabular}

Jurisdictions report bilateral asset and liability positions, expanding the dataset to around 200 countries when counterparties are considered and enabling us to create directed networks capturing the path of the bilateral relationships. It should be noted that while this provides an approximation of the global banking network, it is an incomplete picture since positions among nonreporting countries are not captured; nonreporting countries have a maximum of 66 links (assets + liabilities) in any given year with the reporting countries.

Since we are interested in both the direction and the size of exposures, we characterize the networks using valued matrices rather than binary ones (which would indicate only the existence of a link, not its strength). Given that the matrix (network) size varies throughout our sample period and BIS data is reported in current USD, links are expressed as a fraction of matrix totals (that is, as a fraction of total interbank positions for each year). This allows for comparability across years and adjusts for increased interconnectedness throughout the sample. ${ }^{23}$

\footnotetext{
${ }^{22}$ The beginning of reporting to the BIS varies by jurisdiction. Additional confidential data has also been included for some off-shore financial centers.

${ }^{23}$ For example, a $\$ 100$ link is given a value of 0.5 in a $2 \times 2$ matrix totaling $\$ 200$. If the network in the next year is an $8 \times 8$ matrix totaling $\$ 5,000$, a $\$ 100$ link is relatively less important, receiving a value of only 0.02 . If, however, the $8 \times 8$ matrix totals only $\$ 200$, a $\$ 100$ link is still relatively important within the network despite the existence of additional links, and would be given a value of 0.5 . Note that we do not make adjustments for, or distinguish between, increases in matrix size due to additional BIS reporting countries and increases due to other increases in interconnectedness.
} 
A panel time series is constructed after alter-based centrality scores are calculated for each jurisdiction for each year of the sample.

\section{APPENDIX II}

\section{Simulation Framework}

The simulation framework developed in this appendix builds on earlier work in this area, in particular Nier et al. (2007). In their model of a banking system, nodes (individual banks) are connected to a "source", where the initial shock is generated, and every node is assigned a "sink", where the losses are directed to- the bank's net worth or capital. When losses reach a node, they are absorbed by the sink or, if they are large enough, they trigger a default and flow further through the network via links. Nier et al. (2007) identify external assets as the source of shocks and add depositors to the model as the ultimate sink (loss recipient). They also define a probability distribution that governs whether or not a bank is exposed to another bank through an interbank exposure. They can therefore study varying degrees of connectivity, ranging from non-connected to complete structures in a systematic way.

Our simulations differ from those in Nier et al. (2007) in several respects. In particular, instead of focusing on a banking system in a single country, in which individual banks are the nodes, we are studying the global banking system, where each node represents a country-level banking sector and each link represents a directional lending relationship between two nodes. Another important difference is that the primary focus of Nier et al. (2007) is the relationship between the degree of interconnectedness in the network as a whole and the overall number of defaults in the network; in contrast, our primary focus is the relationship between the centrality of a node within the network and the likelihood of default in that particular node.

The network is based on the following two exogenous parameters that describe the random graph: the number of nodes (i.e., individual countries), $N$, and the probability $p_{i j}$ that a banking sector in country $i$ has lent to a banking sector in country $j$. For the beginning of the analysis, the probability $p_{i j}$ is assumed to be equal across all (ordered) pairs $(i, j)$. The simulation engine then delivers realizations of this graph that conform to the specified parameters and that exhibit a set number $(Z)$ of realized links. For any realization of the random graph, we populate the individual country banking sector balance sheets in a manner consistent with country-level and global balance sheet identities, broadly in line with the approach used by Nier et al. (2007) for individual bank data. In the following text, which describes this in more detail, lower-case letters are used for variables at the country level, capital letters for variables at the global level, and Greek letters for ratios.

An individual banking sector's assets, denoted by $a$, include external assets (investors' borrowing), denoted by $e$, and interbank assets (other banking sectors' borrowing), denoted by $i$. Thus, for banking system $i$, we have $a_{i}=e_{i}+i_{i}$, where $i=1, \ldots, N$. A banking sector's liabilities, denoted by $l$, are composed of the net worth of the banking system, denoted by $c$, its customer deposits, denoted by $d$, and its interbank borrowing, denoted by $b$. Hence for a banking system $i$, we have $l_{i}=c_{i}+d_{i}+b_{i}$, where $i=1, \ldots, N$. And as a balance sheet identity, we have $a_{i}=l_{i}$ for $i=1, \ldots, N$. 
To construct balance sheets for individual banking sectors, we first decide on the total external assets of the global banking system, denoted by $E$. These external assets represent total loans made to ultimate investors and thus relate to the total size of the flow of funds from savers to investors through the banking systems. Next, we decide on the percentage of external assets in total assets $(A)$ at the system level, denoted by $\beta=E / A$. Note that the aggregate assets of the global banking network can be written as $A=E+I$, where $I$ represents the aggregate size of interbank exposures. Hence, for a given aggregate amount of external assets, $E$, the aggregate ratio of external assets to total assets, denoted by $\beta$, delivers both the size of total assets $A$ and the aggregate size of interbank exposures $I$. That is, we have $A=E / \beta$ and $I=\theta A$, where $\theta=(1-\beta)$ is the percentage of interbank assets in total assets. Dividing the total interbank assets by the total number of links $Z$, we arrive at the country-level size (the weight) of any directional link, denoted by $w(w=I / Z)$, which determines how much one country's banking sector lends to another. Hence, using $w$ and the structure of the network, we can calculate $i_{i}$ and $b_{i}$.

To determine the size of each country banking sector's external assets, we assume that its balance sheet satisfies some basic restrictions. In particular, for any banking sector to be able to operate, we require that its external assets are no less than its net interbank borrowing, that is, we have $e_{i} \geq b_{i}-i_{i}$. To ensure that this constraint is fulfilled, we apply the following two-step algorithm. First, for each country's banking system, we fill up its external assets so that its external assets plus interbank lending equal its interbank borrowing, i.e., $e_{i}{ }^{*}+i_{i}=b_{i}$, where $e_{i}{ }^{*}$ is the level of bank $i$ 's external assets we got after this first step. Second, whatever is left in aggregated external assets is evenly distributed among all banks. Note that total external assets equal $E$. Hence, a total of $\left(E-\Sigma e_{i}{ }^{*}\right)$ units of external assets have not been allocated to the individual banking systems' balance sheets yet. In the second step, we distribute this amount equally among all $N$ banking systems. Now, let us denote by $e_{i}^{* *}$ the amount to be allocated to each individual bank, $\left(E-\Sigma e_{i}^{*}\right) / \mathrm{N}$. Hence, we have $e_{i}=e_{i}{ }^{*}+e_{i}{ }^{* *}$.

This completes the asset side of the bank balance sheet as well as interbank borrowing $b$ on the liability side. The remaining components are net worth, $c$, and deposits, $d$, on the liability side. Net worth is determined as a fixed proportion $\gamma$ of total assets at bank level, that is, $c_{i}=\gamma a_{i}$. And consumer deposits take up the remainder to meet the bank's balance sheet identity, that is $d_{i}=a_{i}-c_{i}-b_{i}$.

This completes the construction of the global banking system and of each constituent banking sector's balance sheet. All possible global banking systems constructed in this way can be described by five structural parameters $(\gamma, \theta, p, N, E)$, where $\gamma$ denotes net worth as a percentage of total assets, $\theta$ is the percentage of interbank assets in total assets, $p$ is the probability of any two nodes being connected, $N$ is the number of banks, and $E$ is the total external assets of the banking system.

We focus on the consequences of an idiosyncratic shock affecting the value of a banking sector's external assets in one country and spreading through the global banking network. While it may be possible for a shock to affect several (or all) countries at the same time, idiosyncratic shocks are a cleaner starting point for studying knock-on defaults due to interbank exposures and liquidity effects. Aggregate shocks amount to reducing the net worth of all banks at the same time. If this 
shock is big enough to bring down any bank, in our set-up this will typically lead to all banks defaulting with little scope for further analysis. One can thus think of aggregate shocks as potentially affecting all banks' net worth to a point where none of the banks are yet in default. We then study the consequences of idiosyncratic shocks for any given positive aggregate net worth.

For any given realization of the global banking system, we shock one country banking sector at a time by wiping out a certain percentage of its external assets (the "source" of the shock). Let $s_{i}$ be the size of the initial shock. This loss is first absorbed by the banking system's net worth $c_{i}$, then by its interbank liabilities $b_{i}$, and last by its deposits $d_{i}$, as the ultimate "sink". That is, we assume priority of (insured) customer deposits over bank deposits, which, in turn, take priority over equity (net worth). If the banking sector's net worth is not big enough to absorb the initial shock, the banking sector defaults and the residual is transmitted to creditor banking sectors through interbank liabilities. And if these liabilities are not large enough to absorb the shock, some of the losses are borne by depositors. Formally, if $s_{i}>c_{i}$, then the banking sector defaults. If the residual loss $\left(s_{i}-c_{i}\right)$ is less than the amount $b_{i}$ that banking sector $i$ has borrowed from other banking sectors (i.e., through the crossborder interbank market), then all the residual loss $\left(s_{i}-c_{i}\right)$ is transmitted to creditor banking systems. However, if $\left(s_{i}-c_{i}\right)>b_{i}$, then all of the residual cannot be transmitted to creditor banking systems and depositors take a loss of $\left(s_{i}-c_{i}-b_{i}\right)$.

All creditor banking systems receive an equal share of the residual shock, which in turn, is first absorbed by their net worth. If the net worth is larger than the shock transmitted, the creditor banking system withstands the shock. Otherwise, the creditor banking system "defaults" (has a banking crisis); the residual loss is transmitted through interbank liabilities first, and if these liabilities are not large enough to absorb the shock, the remaining loss is borne by depositors. The part that is transmitted through the interbank channel may cause further rounds of contagious default. The transmission continues down the chain until the shock is completely absorbed.

Formally, let $k$ be the number of creditor banking sectors and let banking sector $j$ be one of those that have lent to banking sector $i$, the banking sector that has been hit by the initial shock. Hence, if $\left(s_{i}-c_{i}\right)<b_{i}$, then banking sector $j$ has a loss of $s_{j}=\left(s_{i}-c_{i}\right) / k$. If $s_{j} \leq c_{j}$, then banking sector $j$ withstands the shock. Otherwise, the creditor banking sector defaults and again the residual loss is transmitted through interbank liabilities, and so forth.

\section{REFERENCES}

Alessi L, Detken C (2009): 'Real Time' Early Warning Indicators for Costly Asset Price Boom/Bust Cycles: A Role for Global Liquidity. European Central Bank Working Paper, no. 1039.

Allen F, Gale D (2000): Financial Contagion. Journal of Political Economy, 108(1):1-33.

Battiston S, Gatti DD, Gallegati M, Greenwald B, Stiglitz J (2010): Liaisons Dangereuses: Increasing Connectivity, Risk Sharing, and Systemic Risk. NBER Working Paper, no. 15611 (Cambridge, MA: National Bureau of Economic Research).

BIS (2010): Research on Global Financial Stability: The Use of BIS International Financial Statistics. CGFS Papers, no. 40 (June). 
Bonacich P (1972): Technique for Analyzing Overlapping Memberships, Sociological Methodology, 4:176-185.

Bonacich P (1987): Power and Centrality: A Family of Measures. American Journal of Sociology, 92(5):1170-82.

Bonacich P, Lloyd P (2001): Eigenvector-like Measures of Centrality for Asymmetric Relations. Social Networks, 23:191-201.

Buch CM, DeLong G (2008): Do Weak Supervisory Systems Encourage Bank Risk-Taking? Journal of Financial Stability, 4:23-39.

Caballero R, Simsek A (2009): Complexity and Financial Panics. NBER Working Paper, no. 14997 (Cambridge, MA: National Bureau of Economic Research).

Calomiris CW, Mason JR (1997): Contagion and Bank Failures during the Great Depression: The June 1932 Chicago Banking Panic. American Economic Review, 87(5):863-83.

Caprio G, Klingebiel D, Laeven L, Noguera G (2005): Appendix: Banking Crisis Database. In: Honohan P, Laeven L (Eds.): Systemic Financial Crises: Containment and Resolution. Cambridge, Cambridge University Press.

Chinn M, Ito H (2008): A New Measure of Financial Openness. Journal of Policy Analysis, 10(3):309-322.

Čihák M, Decressin J (2007): The Case for a European Banking Charter. IMF Working Paper, no. 07/173.

Čihák M, Schaeck K (2010): How Well Do Aggregate Prudential Ratios Identify Banking System Problems? Journal of Financial Stability, 6(3).

Cole A, Gunther J (1998): Predicting Bank Failures: A Comparison of On-and Off-site Monitoring Systems. Journal of Financial Services Research, 13(2).

Davis EP, Karim D (2008): Comparing Early Warning Systems for Banking Crises. Journal of Financial Stability, 4:89-120.

Demirgüç-Kunt A, Detragiache E (2005): Cross-Country Empirical Studies of Systemic Bank Distress: A Survey. IMF Working Paper, no. 05/96.

D'Hulster K (2011): Cross Border Banking Supervision: Incentive Conflicts in Supervisory Information Sharing between Home and Host Supervisors. World Bank Policy Research Working Paper, no. 5871.

Diamond DW, Dybvig PH (1983): Bank Runs, Deposit Insurance, and Liquidity. Journal of Political Economy, 91(3):401-419.

Freixas X, Parigi B, Rochet J (2000): Systemic Risk, Interbank Relations, and Liquidity Provision by the Central Bank. Journal of Money, Credit and Banking, 32(3, Part 2):611-638.

Furfine CH (2003): Interbank Exposures: Quantifying Risk of Contagion. Journal of Money, Credit and Banking, 32(3):611-638.

Gavin M, Hausmann R (1996): The Roots of Banking Crises: The Macroeconomic Context. In: Hausmann R, Rojas-Suárez L (Eds.): Banking Crises in Latin America. New York, Inter-American Development Bank, pp. 27-75.

Gorton G (1988): Banking Panics and Business Cycles. Oxford Economic Papers, New Series, 40(4):751-81.

Gropp R, Vesala J, Vulpes G (2004): Market Indicators, Bank Fragility, and Indirect Market Discipline. Federal Reserve Bank of New York Economic Policy Review, 10(2):53-63.

Hale G (2011): Bank Relationships, Business Cycles, and Financial Crisis. FRBSF Working Papers, no. 14 , May.

Hardy D, Pazarbaşioğlu C (1998): Leading Indicators of Banking Crises: Was Asia Different? IMF Working Paper, no. 98/91.

Huang R, Ratnovski L (2010): The Dark Side of Bank Wholesale Funding. IMF Working Paper, no. $10 / 170$. 
IMF (2010): Integrating Stability Assessments under the Financial Sector Assessment Program into Article IV Surveillance: Background Material. Available at

http://www.imf.org/external/np/pp/eng/2010/082710a.pdf.

IMF/BIS/FSB (2009): Guidance to Assess the Systemic Importance of Financial Institutions, Markets and Instruments: Initial Considerations. October.

Kaminsky G, Lizondo S, Reinhart C (1998): Leading indicators of currency crisis. IMF Staff Paper, no. 1.

Kinney R, Crucitti P, Albert R, Latora V (2005): Modeling Cascading Failures in the North American Power Grid. The European Physics Journal B, 46(1):101-107.

Kubelec C, Sá F (2010): The Geographical Composition of National External Balance Sheets: 1980-2005. Bank of England Working Paper, no. 384.

Laeven L, Valencia F (2008): Systemic Banking Crises: A New Database. IMF Working Paper, no. $08 / 224$.

Laeven L, Valencia F (2010): Resolution of Banking Crises: The Good, the Bad, and the Ugly. IMF Working Paper, no. 10/146.

May RB, Anderson RM (1991): Infectious Diseases of Humans. Oxford University Press.

Miskhin F (1978): The Household Balance Sheet and the Great Depression. Journal of Economic History, 38:918-37.

Minoiu C, Reyes JA (2011): A Network Analysis of Global Banking: 1978-2009. IMF Working Paper, no. 74.

Neal Z (2010): Differentiating Centrality and Power in the World City Network. Urban Studies, vol. $1-16$.

Neal Z (2011): Comparing Beta Centrality and a Modified Degree Centrality. (Presented at Sunbelt XXXI Conference, St. Pete Beach, Florida, February.) mimeo

Nier E, Yang J, Yorulmazer T, Alentorn A (2007): Network Models and Financial Stability. Journal of Economic Dynamics and Controls, 31(6):2033-2060.

Peter G von (2007): International Banking Centres: A Network Analysis. BIS Quarterly Review, December.

Sachs A (2010): Completeness, Interconnectedness and Distribution of Interbank ExposuresA Parameterized Analysis of the Stability of Financial Networks. Deutsche Bundesbank Discussion Paper Series 2: Banking and Financial Studies, no 08/2010.

Soramäki K, Bech LB, Arnold J, Glass RJ, Beyeler WE (2007): The topology of interbank payment flows. Physica A: Statistical Mechanics and its Applications, 379(1):317-333.

Watts D (2002): A Simple Model of Global Cascades on Random Networks'. Proceedings of the National Academy of Sciences, 9:5766-5771.

Wooldrige JM (2005): Simple Solutions to the Initial Conditions Problem in Dynamic, Nonlinear Panel Data Models with Unobserved Heterogeneity. Journal of Applied Econometrics, (20):39-54. 